patients with at least one image per finger. For each patient, we examined number of capillaries (mean number of capillaries per $\mathrm{mm}$ in the distal row), enlarged and giant capillaries, micro-hemorrhages, avascular areas, ramified capillaries, and the presence of a scleroderma (SSc)-like pattern, according to Manfredi et al. Finally, we correlated NVC features with clinical and serological findings of ASSD patients. Results: The NVC of 54 ASSD patients were analyzed (males/females 1/6.8, mean age 55.79, Cl95\% 51.9-59.9 years, mean disease duration 59.4, Cl95\% 27.9-90.9 months). Raynaud's phenomenon (RP) was recorded in $51.9 \%$ of patients, arthritis in $79.6 \%$, myositis in $53.7 \%$, and ILD in $92.6 \%$. NVC alterations were observed in $53.7 \%$ of AASD patients. Nineteen patients $(35.2 \%)$ showed a SSc-like pattern; the main features were disarrangement of hairpin and angiogenetic aspects $(42.6 \%)$, avascular areas $(38.9 \%)$, giant capillaries $(27.6 \%)$, and microhemorrhages $(20.4 \%)$. Finally, the mean number of capillaries was reduced $(7.8 \pm 2 / \mathrm{mm})$. No significant association was recorded between SSc-like pattern and the presence of arthritis, myositis, and ILD, nor with RP. Among other NVC features, angiogenesis was significantly associated to female gender $(p=0.031)$, while microhemorrhages were inversely associated to the presence of arthritis (0.033). No association was observed between NVC features and autoantibodies profile. Of interest, in $58 \%$ of patients with ILD we observed at least a NVC alteration vs no patients without ILD $(p=0.04)$. Finally, in patients with RP NVC alterations were recorded in $15 / 28$ patients $(53.6 \%)$ and a SSc-like pattern in $11 / 28(39.3 \%)$, while only $57.9 \%$ of patients with SSc-like pattern had a clinically manifest Raynaud's phenomenon.

Conclusions: Despite preliminary, the present is the first study concerning NVC in AASD patients. Regardless of the presence of Raynaud's phenomenon, NVC alterations are frequently observed; in particular, a SSc-like pattern is recorded in more than $1 / 3$ of patients. NVC should be performed in all ASSD patients at diagnosis regardless of the presence of RP in the patient history and during follow-up. ASSD should be always considered in the screening of RP. A prospective multicenter study has been planned to identify specific patterns and possible associations between NVC findings and clinical and serological features of ASSD.

References:

[1] Manfredi A, et al. 2015.

[2] Sebastiani M, et al. 2014

Disclosure of Interest: None declared

DOI: 10.1136/annrheumdis-2017-eular.5376

\section{AB0657 SMALL INTESTINAL BACTERIAL OVERGROWTH IN RELATION TO GASTROINTESTINAL SYMPTOMS IN SYSTEMIC SCLEROSIS}

M.D.P. Cruz-Dominguez ${ }^{1}$, G. Garcia-Collinot ${ }^{1}$, E.O. Madrigal-Santillan ${ }^{2}$ A. Carranza-Muleiro ${ }^{1}$, L.J. Jara ${ }^{3}$, D.H. Montes-Cortes ${ }^{4}$, G. Medina-Garcia $^{1}$ O. Vera-Lastra ${ }^{5} \cdot{ }^{1}$ Research Division, Instituto Mexicano del Seguro Social, Hospital de Especialidades CMN la Raza; ${ }^{2}$ Posgrade, IPN, ESM; ${ }^{3}$ Research and Education Direction, Instituto Mexicano del Seguro Social, Hospital de Especialidades CMN la Raza; ${ }^{4}$ Emergency Room, Hospital General CMN la Raza; ${ }^{5}$ Internal Medicine, Instituto Mexicano del Seguro Social, Hospital de Especialidades CMN la Raza, Mexico, Mexico

Background: Autonomic dysfunction, smooth muscle fibrosis and vascular damage lead to small intestinal bacterial overgrowth (SIBO) in Systemic Sclerosis (SSc). SIBO is characterized by diarrhea, abdominal pain, bloating, malabsorption and malnutrition.

Objectives: To evaluate by NIH PROMIS ${ }^{\circledR}$ gastrointestinal symptoms scales and SIBO by hydrogen breath test (HBT) in patients with SSc.

Methods: We include 68 patients with SSc (ACR-EULAR 2015) who signed informed consent. NIH PROMIS ${ }^{\circledR}$ questionarie was applied to evaluated gastrointestinal symptoms and classified in not symptomatic, least, mildy, moderately and most symptomatic. Glucose HBT was applied after 14 hours fast, oral hygiene and 30 days free of antibiotics. Patients who has a negative HBT with symptoms associated to glucose ingestion we repeat test with lactulose.

Results: We applied questionnaire to 58 SSc patients, age 52 (26-75)years, 65 $(96 \%)$ female and $3(4 \%)$ males, disease duration $13(1-40)$ years, limited SSc $41(59 \%)$ and diffuse $27(41 \%)$, body mass index $24(12-39)$.

They are using prednisone (28\%), micofenolate $(14 \%)$, methotrexate $(19 \%)$, azatioprin $(5 \%)$, amlodipine or nifedipine $(33 \%)$. Patients had continuous and very high increase of parts per millon (ppm) of exhaled Hydrogen: min0: $13 \mathrm{ppm}(5-21)$, min15:17 ppm (5-43), min30:17 (3-49), min45:18ppm (7-103), min 60:22ppm (8-145), min90:18ppm (2-250), min120:25ppm (3-212), min150:71ppm (3-235). Normal values: $<10 \mathrm{ppm}$ during total test (Figure1).

Frequency of gastrointestinal symptoms were flatulence (87.5vs81.2\%), nausea/vomiting (72.7vs37.6\%), constipation (65.6vs $40 \%)$, diarrhea (45.2vs $33.4 \%$ ), abdominal pain \%) and incontinence (39.4vs31.3\%) respectively between SCB $(+)$ positive and negative.

Hyperproduction of hydrogen in breath had a direct correlation to severity of their symptoms $(p \leq 0.05)$. The severity of diarrhea was in close relation to the severity of its rectal incontinence $(r=0.73, p=0.001)$, and greater abdominal pain with flatulence $(r=72, p=0.001)$

Conclusions: Gastrointestinal symptoms are common in SSc regardless of whether they have SIBO. However, a higher Row Score SGI or moderate severe status (NIH PROMIS) correlates with high $\mathrm{H}$ scores from the 30th minute, therefore, the questionnaire is useful within the SSc assessment.

\begin{tabular}{|c|c|c|c|c|c|c|}
\hline \multirow{3}{*}{\multicolumn{2}{|c|}{$\begin{array}{l}\text { Spearman Correlation Row Score(NIH } \\
\text { PROMIS) with ppm H+ Test of SIBO }\end{array}$}} & \multicolumn{4}{|c|}{ overgrowth (SIBO) } & \multirow[b]{3}{*}{$p$} \\
\hline & & \multicolumn{2}{|c|}{ Negative } & \multicolumn{2}{|c|}{ Positive } & \\
\hline & & \multirow{2}{*}{$\mathrm{n}=24$} & \multirow{2}{*}{$\begin{array}{c}\% \\
9.8 \%\end{array}$} & \multirow{2}{*}{$\frac{n=44}{2}$} & \multirow{2}{*}{$\begin{array}{c}\% \\
3.9 \%\end{array}$} & \\
\hline Nausea and vomiting & Asymptomatic & & & & & \\
\hline $\mathrm{r}=0.28^{*} \min 45,0.29^{*} \mathrm{mi}$ & Least & 2 & $3.9 \%$ & 2 & $3.9 \%$ & \\
\hline \multirow{3}{*}{$\min 120,0.46^{*} \min 150$} & Mild & 3 & $5.9 \%$ & 6 & $11.8 \%$ & 0.13 \\
\hline & Moderate & 3 & $5.9 \%$ & 7 & $13.7 \%$ & \\
\hline & Severe & 4 & $7.8 \%$ & 17 & $33.3 \%$ & \\
\hline \multirow{5}{*}{$\begin{array}{l}\text { Diarrhea, } \\
r=0.43^{*} \min 120\end{array}$} & Asymptomatic & 3 & $5.9 \%$ & 10 & $19.6 \%$ & \\
\hline & Least & 3 & $5.9 \%$ & 3 & $5.9 \%$ & \\
\hline & Mild & 5 & $9.8 \%$ & 6 & $11.8 \%$ & 0.34 \\
\hline & Moderate & 5 & $9.8 \%$ & 7 & $13.7 \%$ & \\
\hline & Severe & 1 & $2.0 \%$ & 8 & $15.7 \%$ & \\
\hline \multirow{5}{*}{$\begin{array}{l}\text { Constipation } \\
r=0.41^{*} \min 90, \\
0.47^{*} \min 120, \\
0.043^{*} \min 150\end{array}$} & Asymptomatic & 0 & $0.0 \%$ & 4 & $8.2 \%$ & \\
\hline & Least & 2 & $4.1 \%$ & 1 & $2.0 \%$ & \\
\hline & Mild & 8 & $16.3 \%$ & 6 & $12.2 \%$ & 0.05 \\
\hline & Moderate & 2 & $4.1 \%$ & 11 & $22.4 \%$ & \\
\hline & Severe & 4 & $8.2 \%$ & 11 & $22.4 \%$ & \\
\hline \multirow{5}{*}{$\begin{array}{l}\text { Abdominal pain } \\
\mathrm{r}=0.32^{*} \mathrm{~m} 120\end{array}$} & Asymptomatic & 1 & $2.0 \%$ & 0 & $0.0 \%$ & \\
\hline & Least & 7 & $13.7 \%$ & 9 & $17.6 \%$ & \\
\hline & Mild & 6 & $11.8 \%$ & 8 & $15.7 \%$ & 0.16 \\
\hline & Moderate & 1 & $2.0 \%$ & 4 & $7.8 \%$ & \\
\hline & Severe & 2 & $3.9 \%$ & 13 & $25.5 \%$ & \\
\hline \multirow{5}{*}{$\begin{array}{l}\text { Distension } \\
\mathrm{r}=0.36^{*} \mathrm{~m} 0,0.35^{*} \mathrm{~min} 15, \\
0.3^{*} \mathrm{~min} 45,0.37^{*} \mathrm{~min} 60, \\
0.386^{*} \mathrm{~min} 90,0.36^{*} \mathrm{~min} \\
120\end{array}$} & Asymptomatic & 1 & $2.0 \%$ & 1 & $2.0 \%$ & \\
\hline & Least & 2 & $4.0 \%$ & 1 & $2.0 \%$ & \\
\hline & Mild & 1 & $2.0 \%$ & 2 & $4.0 \%$ & 0.08 \\
\hline & Moderate & 8 & $16.0 \%$ & 6 & $12.0 \%$ & \\
\hline & Severe & 5 & $10.0 \%$ & 23 & $46.0 \%$ & \\
\hline \multirow{5}{*}{$\begin{array}{l}\text { Incontinence } \\
r=0.28^{*} \min 45 \\
0.37^{*} \min 120\end{array}$} & Asymptomatic & 8 & $15.7 \%$ & 17 & $33.3 \%$ & \\
\hline & Least & 0 & $0.0 \%$ & 0 & $0.0 \%$ & \\
\hline & Mild & 5 & $9.8 \%$ & 3 & $5.9 \%$ & 0.24 \\
\hline & Moderate & 2 & $3.9 \%$ & 8 & $15.7 \%$ & \\
\hline & Severe & 2 & $3.9 \%$ & 6 & $11.8 \%$ & \\
\hline
\end{tabular}

Disclosure of Interest: None declared

DOI: 10.1136/annrheumdis-2017-eular.6824

\section{AB0658 FACTORS INFLUENCING ELAPSED TIME TO A DEFINITIVE DIAGNOSIS OF SYSTEMIC SCLEROSIS AND THEIR RELATIONSHIP WITH THE NUMBER OF ATTENDING PHYSICIANS AND THEIR MEDICAL SPECIALIZATION}

Y. Erez ${ }^{1}$, H. Yarkan Tugsal ${ }^{2}$, G. Kenar ${ }^{2}$, B. Zengin ${ }^{2}$, D. Solmaz ${ }^{3}$, M. Ozmen ${ }^{3}$, G. Can ${ }^{2}$, N. Akkoc ${ }^{2}$, F. Onen ${ }^{2}$, M. Birlik ${ }^{2} .{ }^{1}$ Internal Medicine; ${ }^{2}$ Rheumatology, Dokuz Eylul University School of Medicine; ${ }^{3}$ Rheumatology, Katip Celebi University School of Medicine, Izmir, Turkey

Background: The diagnosis of Systemic Sclerosis (SSc) can be difficult due to its rarity and heterogeneity. In addition, not all physicians are expert in the identification of patients with early SSc features.

Objectives: The aim of this study was to investigate factors influencing the time elapsed since a proper diagnosis of SSc and their relationship with the number of attending physicians and their specialization, among Turkish patients. In Turkish healthcare system,each patient may directly go to the hospitals and choose appropriate care facility and physician.

Methods: The study covers 240 SSc patients who were diagnosed according to 1980 ACR criteria in the rheumatology database at the University of Dokuz Eylul, Izmir. Data included demographics, SSc duration, SSc subtype, physical examinations (mRodnan Score-mRS), and a face-to-face structured interview. Cases were excluded if they couldn't recall date of initial symptoms and all the prior attending physicians including their specialization until a definitive diagnosis of SSc. As clinical characteristics are different than pure SSc patients, overlap syndromes were excluded. Mann-Whitney $U$ test was used to assess the difference between dependent and independent variables. The association between mRS and dependent variables was evaluated by Spearman correlation test.

Results: Remaining 135 patients (F:88.8\%), mean age $\pm S D$ ( $52.14 \pm 11.58$ years) identified. $55(41 \%)$ patients had diffuse and $80(59 \%)$ patients had limited disease. $119(88 \%)$ patients SSc diagnosed by a rheumatologist however, 48 patients $(35 \%)$ were first seen by an internist. Median time to diagnosis was 36 months (1-588) from the onset of Raynaud Phenomenon (RF) and 11 months (0-397) from the onset of the first non-RF symptom for our cases. Relation between some parameters and time to diagnosis were shown in Table.1. Mean number of attending physicians until SSc diagnosis was calculated as 3,54 $(\mathrm{SD} \pm 1,66)$. None of the demographic and clinical parameteres (SSc subtype, mRS, symptom duration) were related with the number of attending physician. There was no correlation detected between mRS and time to diagnosis and number of attending physicians. Nevertheless it was established that median number of physicians was less for patients who were referred to a proper clinician by their familier healthcare practitioners ( $p: 0,019)$. 